\section{A new angle on throwing}

A long throw-in can be a powerful weapon in football. As the World Cup gets under way, Nick Linthorne explains the physics behind the perfect throw-in

It's Sunday 25 June 2006 and we are five minutes into the first half of the England versus Germany match. The ball goes out of play not far from the German goalline. Gary Neville sends a long throw-in over to the far post, Michael Owen gets a touch and it's a goal. England go 1-0 up!

As this hypothetical situation illustrates, a long throw-in - which involves launching the ball with both hands from behind the head - can make a big difference to a game of football. Neville is the long-throw specialist for the England team: he can dispatch the ball some $30-40 \mathrm{~m}$ from the sideline and provide his team mates with a great opportunity to score. But how can a player maximize the range of his or her throw? In other words, at what angle should the player throw the ball to make it travel as far as possible?

Solving the equation of motion for a projectile yields an answer of $45^{\circ}$. But watch a footballer take a long throw-in and you will notice that the ball is often launched at nearer to $30^{\circ}$. The reason for the disparity lies in the biomechanical structure of the human body.

\section{The physics of throw-ins}

The range of a projectile is strongly dependent on the velocity with which it is released, but it also depends on the angle of release (defined with respect to the horizontal). In terms of basic physics, the optimum launch angle is a simple trade-off between the projectile's vertical velocity, which increases the flight time, and horizontal velocity, which increases the distance the projectile travels while airborne. According to most physics textbooks, the optimum angle is $45^{\circ}$. This result is obtained by taking the equation for the range of a projectile in free flight and then either differentiating the equation with respect to launch angle or plotting the range as a function of launch angle and then looking where the peak lies. However, this approach assumes that the launch velocity is independent of the launch angle, something that is often not true for sportspeople.

To overcome this limitation, I and an undergraduate student of mine, David Everett, used a video camera and biomechanical-analysis software to measure how a footballer's throwing speed varies with throwing angle. We found that the footballer was able to launch the ball

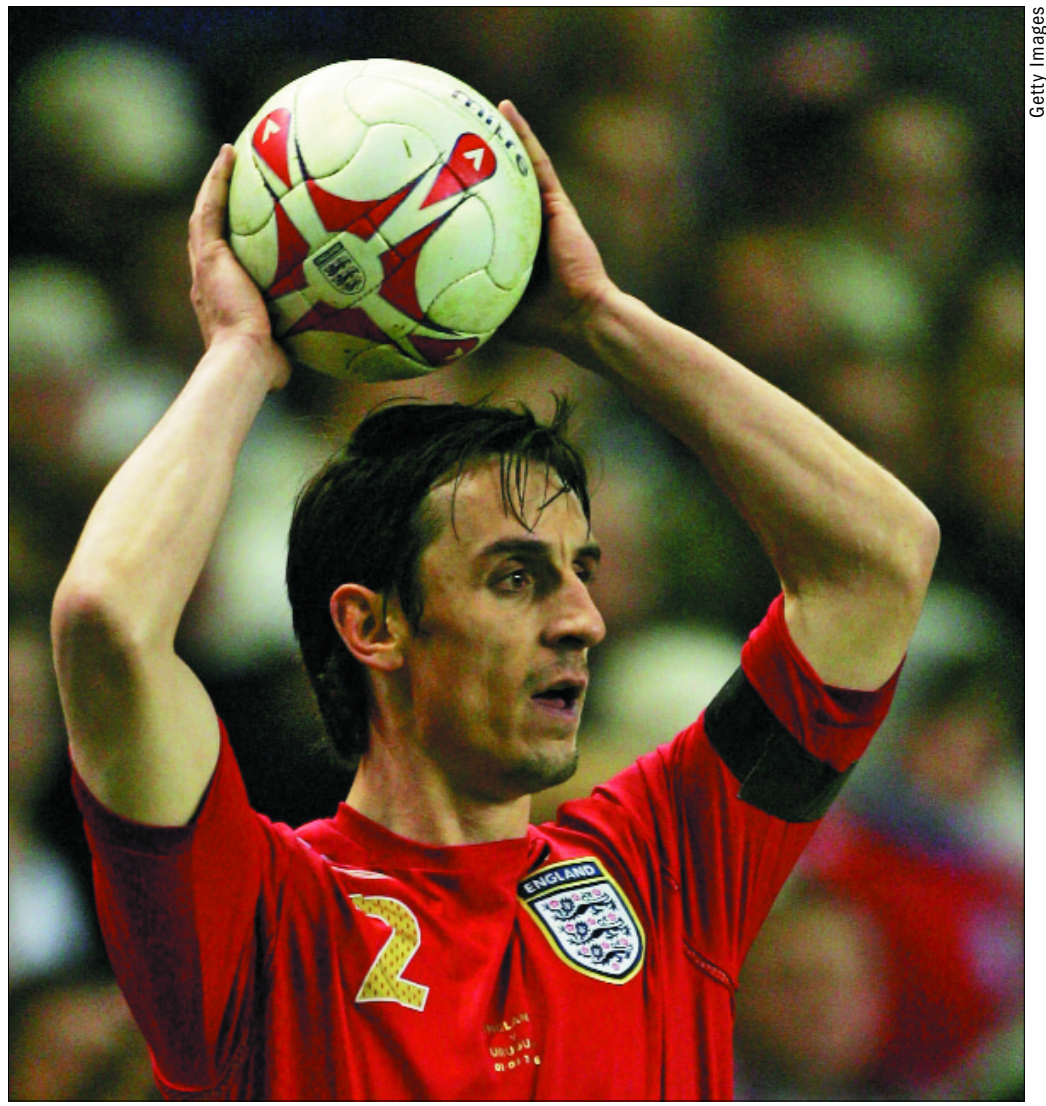

considerably faster at lower angles. This is because the arrangement of muscle levers in the arms and back allows you to exert more throwing force in the horizontal direction than in the vertical direction. To convince yourself of this, try doing a throw-in at a range of angles. You will find that it is much more difficult to throw a ball straight up than it is to throw a ball straight ahead.

The first step in calculating the optimum launch angle was to obtain a mathematical expression relating release velocity to release angle:

$$
v=\sqrt{\frac{2\left(F_{\mathrm{o}}-a \theta\right) l}{m}}
$$

where $v$ is the release velocity, $F_{\mathrm{o}}$ the average force exerted by the player for a horizontal projection angle, $a$ is a constant, $\theta$ is the release angle, $l$ is the length over which the ball is accelerated, and $m$ is the mass of the ball. The equation was derived using a simple physical model and the constants obtained by fitting the equation to the data.

The next step was to insert this expression into the equation for the range of a projectile:

$$
R=\frac{v^{2} \sin 2 \theta}{2 g}\left[1+\left(1+\frac{2 g h}{v^{2} \sin ^{2} \theta}\right)^{1 / 2}\right]
$$

where $R$ is the range of the projectile, $g$ is the acceleration due to gravity, and $h$ is the height difference between launch and landing. By plotting $R$ as a function of angle, we found that the optimum release angle was $30^{\circ}$, which agreed well with what the player did in practice (Sports Biomechanics at press).

In our study we considered aerodynamic drag and the lift due to the spinning of the ball, but these had little effect on the result. The angle will also vary between
Long-throw specialist England's Gary Neville throws the ball using a relatively flat trajectory to achieve the greatest distance.
Nick Linthorne researches and teaches the physics of sports at Brunel University, Uxbridge, UK, e-mail nick. linthorne@brunel. ac.uk 


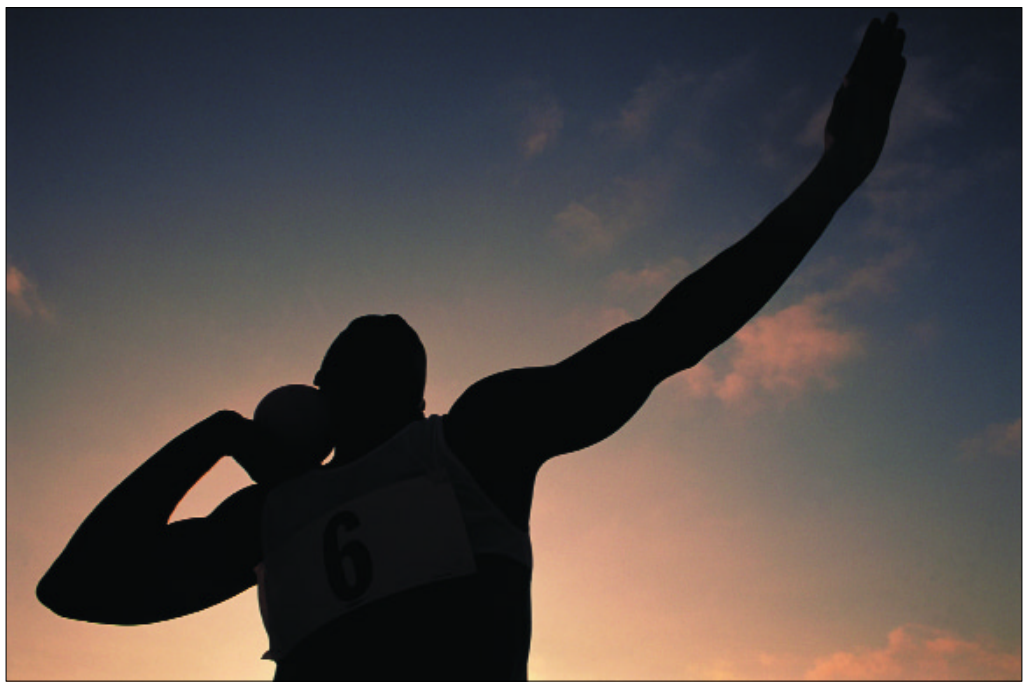

Aiming low Shot-putters also throw at a lower angle to the horizontal than might be expected.

players, because they will have different limb lengths, muscle strengths and throwing techniques. Nevertheless, most players have an optimum launch angle of between $25-35^{\circ}$.

\section{Optimizing athletics}

Of course, football is not the only sport that involves throwing. The same physical principles can also be applied to athletics. While I was a PhD student in Australia I was quite a good athlete, and one of my training partners Paul Jeffrey attended a training camp for shot-putters at the Australian Institute of Sport in Canberra in preparation for the World Athletics Championships. Sports scientists at the institute told him he would throw about $50 \mathrm{~cm}$ further if he raised his release angle from his usual $32^{\circ}$ up to the "optimum" angle of $41^{\circ}$. (This is slightly less than $45^{\circ}$ because the shot is launched from about $2 \mathrm{~m}$ above ground level.) But I had seen studies showing that the world's best shot-putters release the shot at angles as low as $30^{\circ}$. I reckoned that these athletes would have worked out what was best through thousands of hours of trial and error, and I suggested to Paul that the advice he had been given was flawed and that he should continue throwing at $32^{\circ}$, which he did.

Subsequently, while at the University of Sydney, I obtained data on five shot-putters from a study by Andreas Maheras at the University of Kansas. He found that all five athletes could throw less quickly as they increased their release angle from $20^{\circ}$ to $60^{\circ}$. As I would do later with footballers, I substituted a mathematical equation linking release velocity and release angle into the projectile equation and found that the optimum release angle matched those used by the athletes - that is $32-35^{\circ}$. And as with footballers, it is the the structure of the human body that favours horizontal over vertical throwing. If you consider just upper body strength, most athletes can lift more weight in a bench-press exercise - which requires horizontal force - than in a shoulder-press exercise - which needs vertical force.

This work on shot-putting echoes earlier research on the javelin carried out by Ed Red, a mechanical engineer at the University of New Mexico and a former Olympic javelin thrower. Although the flight of a javelin requires more complicated equations than that of a shot-put because it is highly aerodynamic, Red nev-

\section{The range of a projectile is strongly dependent on the velocity with which it is released, but it also depends on the angle of release}

ertheless worked out these equations. He then combined them with an expression relating release velocity and release angle, having measured this relation in three athletes (himself included). His calculated optimum release angle - about $37^{\circ}$ - agreed well with the angles used by the javelin throwers in practice.

The same reasoning can also be applied to the long jump, since a long jumper has a low drag-to-weight ratio and so acts like a projectile in free flight. The jumper generates his or her projection velocity through a combination of the horizontal velocity developed in the run-up and the vertical velocity generated during take-off. By running at full speed and then jumping as high as possible, an athlete can achieve projection velocities of about $10 \mathrm{~m} \mathrm{~s}^{-1}$ but projection angles only up to a maximum of about $25^{\circ}$. Greater projection angles require slower run-ups, and so the projection velocity is less. I measured the relation between projection velocity and projection angle for three worldclass long jumpers and used the same technique for calculating the optimum projection angle as that used for the shot-put. Again my calculated optimum projection angle $-20-25^{\circ}$ - was in good agreement with what the athletes did in practice.

\section{Research benefits}

There is one caveat to all this research, however: I have found that it cannot be used to significantly improve the performance of any sportspeople. Most athletes work out their optimum launch angle by trial and error, and do not need a scientist to tell them what to do. But this work does have a use: it is a great way of bringing physics to life. The physics of sports is fun, and I encourage everyone to dabble in the scientific underpinnings of their favourite sport.

It is also worth bearing in mind that sport is now big business, and it is possible to make a career in the physics of sport if you are keen enough. While in most instances scientists cannot improve the performance of elite athletes, they can make a significant contribution to sports engineering, such as designing better sports equipment and training devices. And who knows, maybe the top sportspeople might be curious to understand the science underlying their performances. Perhaps Gary Neville will thank physics if he makes that vital throw-in in a few weeks' time. 